\title{
Recent Advances in the Ultrasound-Assisted Synthesis of Azoles
}

\author{
Lucas Pizzuti ${ }^{1}$, Márcia S.F. Franco ${ }^{1}$, Alex F.C. Flores ${ }^{2}$, \\ Frank H. Quina ${ }^{3}$ and Claudio M.P. Pereira ${ }^{4}$ \\ ${ }_{1}^{1}$ Universidade Federal da Grande Dourados, Mato Grosso do Sul \\ ${ }^{2}$ Universidade Federal de Santa Maria, Rio Grande do Sul \\ ${ }^{3}$ Instituto de Química, Universidade de São Paulo, São Paulo \\ ${ }^{4}$ Universidade Federal de Pelotas, Rio Grande do Sul \\ Brazil
}

\section{Introduction}

The ever increasing awareness of the need to protect natural resources through the development of environmentally sustainable processes and the optimization of energy consumption has guided the actions of both the private and governmental sectors of society. Economic planning has been strongly impacted by this new paradigm, which has led to increasing demands by society for products produced in a sustainable way and to more stringent governmental regulatory policies. Thus, while in the past profit was often the major concern, in the current economic context more sustainable production processes are preferred. This has triggered a demand in both industry and academy for the development of new, cleaner technologies.

In the field of chemistry and chemical technology, the 12 principles of Green Chemistry provide a set of clear guidelines for the development of new synthetic methodologies and chemical processes and for the evaluation of their potential for environmental impact. As a consequence, in organic chemistry, numerous investigations now routinely use nontradicional synthetic metodologies such as solvent-free reactions, the application of alternative activation techniques like microwaves or ultrasound, the replacement of volatile organic solvents by water, ionic liquids, or supercritical $\mathrm{CO}_{2}$, etc.

In medicinal chemistry, experience has shown that compounds with biological activity are often based on heterocyclic structures. In particular, azoles and their derivatives have attracted increasing interest as versatile intermediates for the synthesis of biologically active compounds such as potent antitumour, antibacterial, antifungal, antiviral and antioxidizing agents. Azoles are a large class of 5-membered ring heterocyclic compounds containing at least one nitrogen atom and one heteroatom in their structure. The construction of this type of molecule has received great attention due to the wide spectrum of biological activities that have been attributed to structurally distinct azoles. Fluconazole, itraconazole, voriconazole and posaconazole are antifungal agents commercially available that contain a triazole nucleus. Celecoxib is a non-steroidal anti-inflammatory and analgesic agent of the 
pyrazole class. Isoxazole compounds such as valdecoxib are selective COX-2 inhibitors used in the treatment of pain. In this context, much attention has been given by researchers in universities and pharmaceutical industries to the development of new, energy saving, costeffective, environmentally safe technologies for the synthesis of azoles.

In this context, the use of ultrasound to accelerate reactions has proven to be a particularly important tool for meeting the Green Chemistry goals of minimization of waste and reduction of energy requirements (Cintas \& Luche, 1999). Applications of ultrasonic irradiation are playing an increasing role in chemical processes, especially in cases where classical methods require drastic conditions or prolonged reaction times. The excellent review of Cella and Stefani (Cella \& Stefani, 2009), which covered the available literature up to about three years ago, clearly showed the importance of taking advantage of the unique features of ultrasound-assisted reactions to synthesize heterocyclic ring systems. The present chapter will therefore limit its coverage of the literature to the period of the last three years and focus on the use of ultrasound to promote the cyclization reactions employed to obtain azoles. Modifications of side chains are not covered in this work. After a brief consideration of ultrasound and the origin of its effects on chemical reactions, a total of 42 reports of the preparation of azoles under conditions of ultrasonic irradiation are reviewed, including several of our own contributions to this field of research. These reports were grouped together according to the number of heteroatoms present in the ring $(2,3$ or 4$)$ and each group subdivided by the azole class. Reports in which more than one class of azoles were prepared were collected in the last section, labelled "Miscellaneous".

\section{Ultrasound and its chemical effects}

The discovery of the piezoelectric effect in the 1880s provided the basis for the construction of modern ultrasonic devices. Piezoelectric materials generate mechanical vibrations in response to an applied alternating electrical potential. If the potential is applied at sufficiently high frequency, ultrasonic waves are generated. The phenomenon responsible for the beneficial effects of ultrasound on chemical reactions is cavitation. Ultrasonic waves are propagated via alternating compressions and rarefactions induced in the transmitting medium through which they pass. During the rarefaction cycle of the sound wave, the molecules of the liquid are separated, generating bubbles that subsequently collapse in the compression cycle. These rapid and violent implosions generate short-lived regions with local temperatures of roughly $5000^{\circ} \mathrm{C}$, pressures of about $1000 \mathrm{~atm}$ and heating and cooling rates that can exceed 10 billion ${ }^{\circ} \mathrm{C}$ per second. Such localized hot spots can be thought of as micro reactors in which the mechanical energy of sound is transformed into a useful chemical form. In addition to the generation of such hot spots, there can also be mechanical effects produced as a result of the violent collapse (Mason \& Lorimer, 2002).

More than 80 years have passed since the effect of ultrasound on reaction rates was first reported by Richards and Loomis (Richards \& Loomis, 1927). However, this work received little attention at the time because it used a high-frequency apparatus that was not commonly available to chemists. According to the review of Cravotto and Cintas (Cravotto \& Cintas, 2006), two classical papers, published in 1978 and 1980, provided a major stimulus for the development of modern sonochemistry: (1) the report by Fry and Herr (Fry \& Herr, 1978) of the reductive dehalogenation of dibromoketones with mercury dispersed by ultrasound; and (2) the work of Luche and Damiano (Luche \& Damiano, 1980) on the 
sonochemical preparation of organolithium and Grignard reagents and their coupling with carbonyls. In the ensuing four decades, numerous efficient and innovative applications of ultrasound in organic synthesis have appeared, which have established sonochemistry as an important tool in the arsenal of Green Chemistry.

The two main sources of ultrasound in organic synthesis are ultrasonic cleaning baths and ultrasonic immersion probes, which typically operate at frequencies of 40 and $20 \mathrm{kHz}$, respectively (Mason, 1997). The former are more commonly employed in organic synthesis simply because they are less expensive and hence more widely available to chemists, even though the amount of energy transferred to the reaction medium is lower than that of ultrasonic probe systems, which deposit the acoustic energy directly into the reaction medium.

\section{Azoles with two heteroatoms}

\subsection{Pyrazole derivatives}

1,5-Diarylpyrazoles (3) can be prepared by the reaction between Baylis-Hillman adducts (1) and phenylhydrazine hydrochloride (2) in 1,2-dichloroetane under sonication with reaction times of 60-180 minutes (Scheme 1) (Mamaghani \& Dastmard, 2009). The reactions proceeded regioselectively to afford the desired products in $80-90 \%$ yields. The same reaction carried out by simply heating the reaction mixture $\left(80^{\circ} \mathrm{C}\right)$ produced the products in lower yields (60-75\%) and required longer reaction times $(6-9 \mathrm{~h})$.
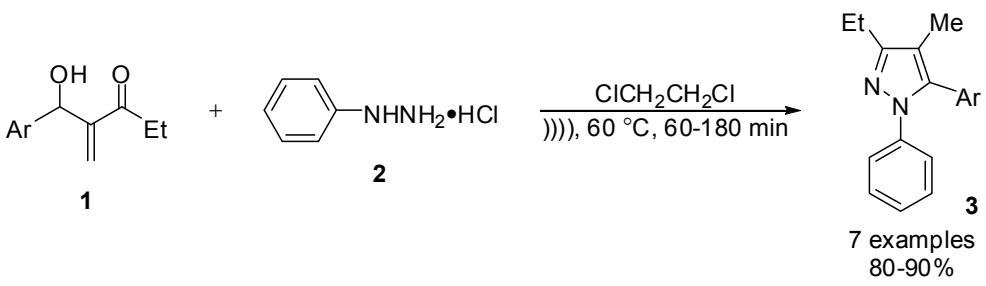

Scheme 1.

In 2009, Pathak and co-workers (Pathak et al., 2009) conducted a comparative study between four activating methods for obtaining $N$-acetyl-pyrazolines (7), including reflux, solvent-free conditions, microwave irradiation and ultrasonic irradiation. Microwave irradiation was found to be the most efficient activating method, followed by ultrasound. Employing ultrasound, the reactions of 1,4-pentadien-3-ones (4) with hydrazine (5) and acetic acid (6) in ethanol went to completion in 10-25 minutes and afforded the products (7) in good yields (Scheme 2).<smiles>[R]c1ccc(/C=C/C(=O)/C=C/c2cc#[R]cc2)cc1</smiles>

4<smiles>CC(=O)ON</smiles>

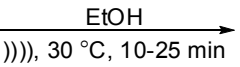<smiles>[R]c1ccc(/C=C/C2=NN(C(C)=O)C(c3ccccc3)C2)cc1</smiles>

10 examples $76-91 \%$

Scheme 2 . 
Previously, we described a greener, ultrasound-assisted synthesis of 1-thiocarbamoyl-3,5diaryl-4,5-dihydropyrazoles (10) from chalcones (8) and thiosemicarbazide (9) catalyzed by $\mathrm{KOH}$ (Scheme 3) (Pizzuti et al., 2009). The products were obtained in high purity and in good yields in only 20 minutes via a simple filtration of the reaction mixture.<smiles>NC(=S)NNC(=O)OCCO</smiles>

Scheme 3 .

Similarly, in 2010, we reported the cyclization of chalcones (11) with aminoguanidine hydrochloride (12) under essentially the same conditions (Scheme 4) (Pizzuti et al., 2010). The 4,5-dihydropyrazole derivatives (13) were obtained in high yields in 30 minutes employing sonication. The same reactions carried out under reflux without ultrasonic irradiation afforded the products in lower yields (57-69\%) and required substantially longer reaction times (3-6 h).<smiles>[R]c1ccc(/C=C/C(=O)c2ccccc2)cc1</smiles>

11<smiles>N=C(N)NNCCCCCO</smiles>

12<smiles>N=C(N)N1N=C(c2ccccc2)CC1c1ccccc1</smiles>

Scheme 4 .

Gupta and co-workers utilized an ultrasonic cleaning-bath to promote the cyclization reaction between chalcones (14) and phenylhydrazine (15) under acid conditions, giving the desired cyclization products (16) in good yields (Scheme 5) (Gupta et al., 2010).<smiles>[R]c1ccc(C(=O)/C=C/c2ccc(Cl)cc2)cc1</smiles>

14
$\mathrm{AcOH}$ $\overrightarrow{7))), 25-40{ }^{\circ} \mathrm{C}, 30-100 \mathrm{~min}}$<smiles>[R]c1ccc(C2=NN(c3ccccc3)C(c3ccc(Cl)cc3)C2)cc1</smiles>

Scheme 5. 
A multicomponent ultrasound-assisted protocol for the synthesis of bridgehead pyrazole derivatives (20) was developed by Nabid and co-workers (Nabid et al., 2010). Under ultrasonic irradiation, the reaction between phthalhydrazide (17), malononitrile or ethyl cyanoacetate (18), and aromatic aldehydes (19) in the presence of triethylamine furnished $1 H$-pyrazolo[1,2-b]phthalazine-5,10-diones (20) in very good yields (Scheme 6).

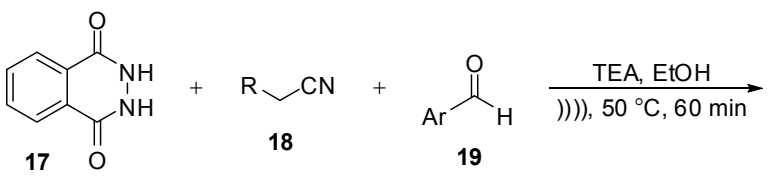

Scheme 6.

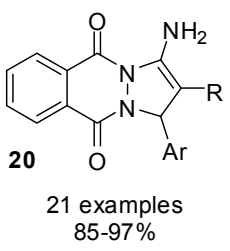

3-Aryl-2,3-epoxy-1-phenyl-1-propanone (21) reacted under ultrasonic irradiation with phenylhydrazine (22) catalyzed by $\mathrm{HCl}$ at room temperature to produce 1,3,5triarylpyrazoles (23) in 69-99\% yields (Scheme 7) (Li et al., 2010). The same reactions performed in the absence of sonication gave substantially poorer yields.

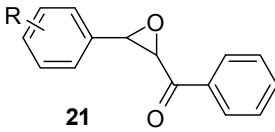

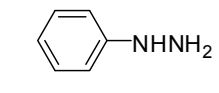

22
$\underset{\mathrm{HCl}, \mathrm{EtOH}), \mathrm{rt}, 45-165 \mathrm{~min}}{\longrightarrow}$

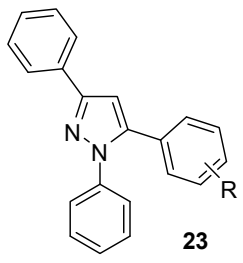

10 examples $69-99 \%$

Scheme 7.

3,4-Dimethyl-2,4-dihydropyrazolo[4,3-c][1,2]benzothiazine 5,5-dioxide (26) was prepared in only 10 minutes by the cyclization of 1-(4-hydroxy-2-methyl-1,1-dioxido-2H-1,2benzothiazin-3-yl)ethanone (24) with hydrazine (25) under ultrasonic irradiation (Scheme 8) (Ahmad et al., 2010). The product was used for the preparation of acetohydrazide derivatives with potential antioxidant and antibacterial activities.<smiles>CC(=O)C1=C(O)c2ccccc2S(=O)(=O)N1C</smiles>

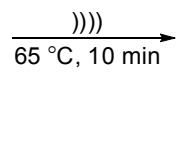<smiles>Cc1[nH]nc2c1N(C)S(=O)(=O)c1ccccc1-2</smiles>

Scheme 8 .

In 2010, ultrasound was employed to promote the synthesis of pyrazolones (29) via the reaction of $\beta$-keto esters (27) with hydrazine derivatives (28) in ethanol. The reactions went to completion in short times $(2-25 \mathrm{~min})$ and afforded the products in $4-93 \%$ yields (Scheme 9) (Al-Mutairi et al., 2010). 
<smiles>[R]C(=O)CC(=O)OCC</smiles>
27
28

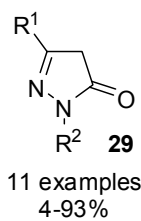

Scheme 9 .

Recently, Machado and co-workers (Machado et al., 2011) reported the preparation of several ethyl 1-(2,4-dichlorophenyl)-1H-pyrazole-3-carboxylates (32) that are structurally analogous to the CB1 receptor antagonists used in the treatment of obesity. Cyclization of 4alkoxy-2-oxo-3-butenoic ester (30) and 2,4-dicholorophenyl hydrazine hydrochloride (31) under sonication (10-12 $\mathrm{min}$ ) or conventional thermal conditions $(2.5-3 \mathrm{~h})$ regioselectivelly afforded the desired products (Scheme 10). The use of ultrasound proved to be fundamental for reducing the reaction time.<smiles>[R]C(=O)C([R])=C([R])OCC</smiles>

30<smiles>NNc1ccc(Cl)cc1Cl</smiles>

31<smiles>[R]c1c(C(=O)OCC)nn(-c2ccc(Cl)cc2Cl)c1[R]</smiles>

14 examples $71-92 \%$

Scheme 10.

A rapid procedure for obtaining acetylated bis-pyrazole derivatives (36) was based on the sonication of bis-chalcones (33) and hydrazine (34) in the presence of acetic anhydride (35) during 10-20 minutes (Scheme 11) (Kanagarajan et al., 2011). The same reactions required 5-8 $\mathrm{h}$ to go to completion when carried out under heating in the absence of ultrasound and afforded lower yields (55-70\%) than those of sonochemical-assisted reaction.
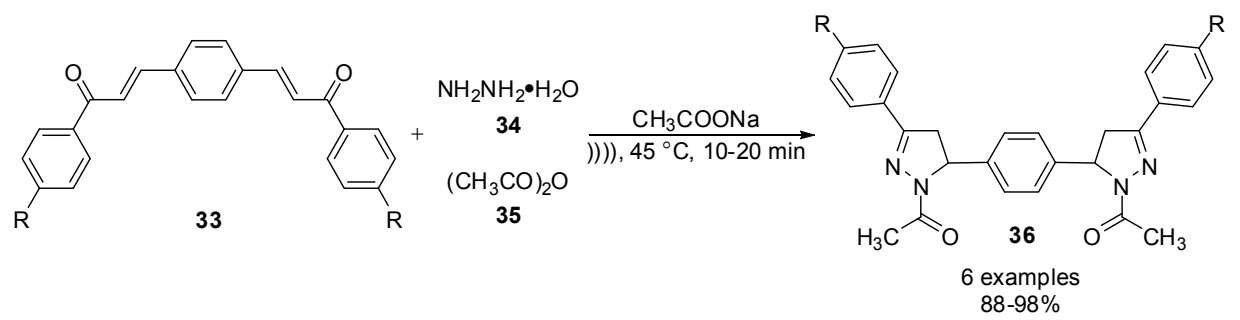

Scheme 11.

A four-component one-pot reaction of ethyl acetoacetate (37), aromatic aldehydes (38), hydrazine (39), and malononitrile (40) in water afforded dihydropyrano[2,3-c]pyrazoles (41) in good yields under ultrasonic irradiation (79-95\%) (Scheme 12) (Zou et al., 2011). Again, a comparative study in the absence of ultrasound showed that the products were obtained in lower yields (70-86\%) and demanded longer reaction times (1-5 h). 


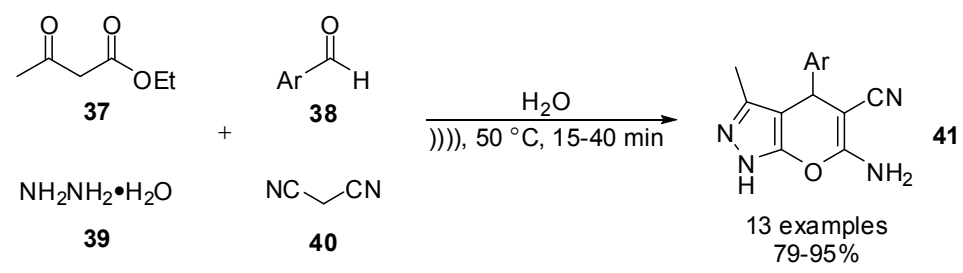

Scheme 12 .

Both microwave and ultrasonic irradiation promoted de reaction of nitrile derivatives (42) with hydrazines (43) (Rodrigues-Santos \& Echevarria, 2011). The reaction was highly regioselective and produced only one isomer (44) in 70-95\% yields after 3 hours under sonication (Scheme 13). Although microwave irradiation required a much shorter reaction time (15 $\mathrm{min})$, the yields were much lower (40-65\%) than with ultrasound. However, ultrasound was not effective for the preparation of phenylhydrazine derivatives.

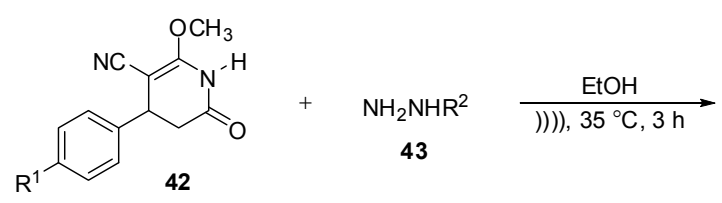<smiles>[R]c1ccc(C2CC(=O)Nc3c2c(N)nn3[R])cc1</smiles>

Scheme 13.

Very recently, Shekouhy and Hasaninejad (Shekouhy \& Hasaninejad, 2012) reported the rapid and efficient preparation of $2 \mathrm{H}$-indazolo[2,1-b]phthalazine-triones (49) (Scheme 14). Their four-component one-pot methodology consisted of the reaction of phthalic anhydride (45), dimedone (46), and hydrazine hydrate (47) with several aromatic aldehydes (48) in an ionic liquid under sonication. The products were obtained in good to excellent yields in very short reaction times.
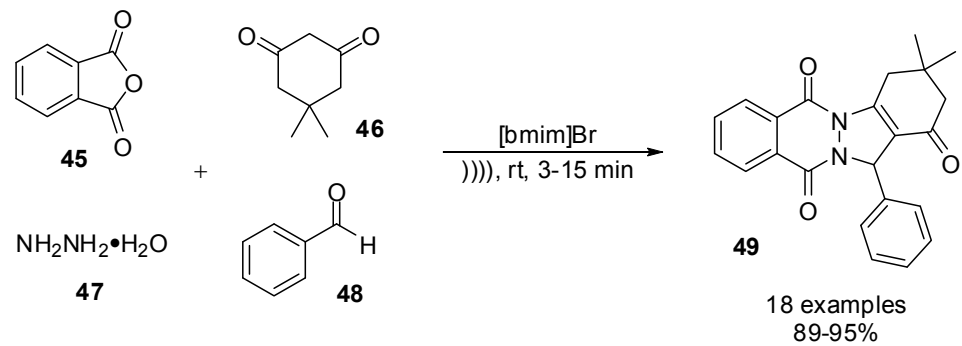

Scheme 14 .

\subsection{Imidazole derivatives}

In connection with reactions in aqueous media, low potency (50 Watts) sonochemistry has been used to prepare 2-imidazolines (52) from the reaction of aldehydes (50) with 
ethylenediamine (51) and NBS (N-bromosuccinimide) as catalyst (Scheme 15) (Sant'Anna et al., 2009). The compounds were isolated in high yields (80-99\%) and required only short reaction times (12-18 minutes). The isolated compounds showed bioactivity as monoamine oxidase (MAO) inhibitors.

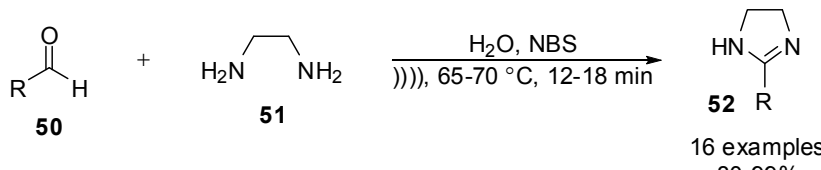

Scheme 15.

$80-99 \%$

Shelke and co-workers (Shelke et al., 2009) reported the synthesis of 2,4,5-triaryl-1Himidazoles (57) from the three-component one-pot condensation of benzil (53)/benzoin (54), aldehydes (55) and ammonium acetate (56) in aqueous media under ultrasound at room temperature (Scheme 16). $\mathrm{BO}_{3} \mathrm{H}_{3}(5 \mathrm{~mol} \%)$ was used as catalyst. The reaction, performed under conventional stirring without ultrasound, required a reaction time (180 minutes) clearly longer than those require when ultrasound was used.

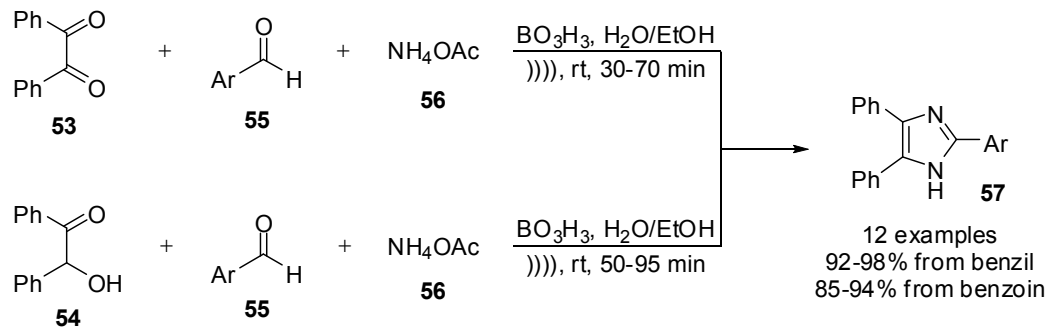

Scheme 16.

$\mathrm{Li}$ and co-workers (Li et al., 2010) reported the synthesis of glycoluril derivatives catalyzed by potassium hydroxide in $\mathrm{EtOH}$ under ultrasonic irradiation (Scheme 17). Although the reaction was relatively efficient, it was not selective. Two products were isolated, the desired glycoluril (60) (17-75\%) together with a hydantoin co-product (61) (1-37\%).

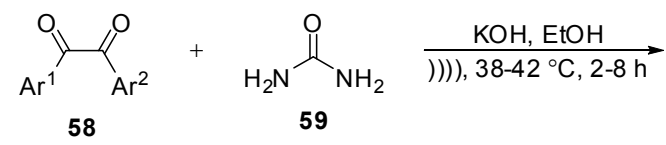

Scheme 17.

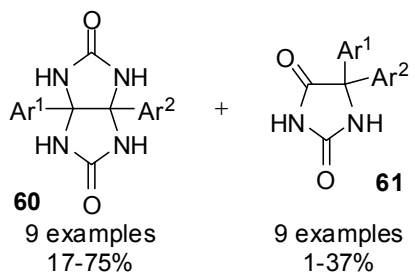

Zang and co-workers (Zang et al., 2010) reported a three-component one-pot synthesis of 2aryl-4,5-diphenyl imidazoles (65) at room temperature under ultrasonic irradiation (Scheme 18). The ionic liquid 1-ethyl-3-methylimidazole acetate ([emim]OAc) was used as catalyst 
and the desired products obtained in satisfactory yields. Ionic liquids have shown great potential as catalysts and are a particularly attractive alternative to conventional catalysts. Their ability to dissolve a wide variety of substance and their potential for recyclability are among the attributes responsible for their recent popularity.<smiles>O=C(C(=O)c1ccccc1)c1ccccc1</smiles>

62<smiles>NNC(=O)[OH2+]</smiles>

63

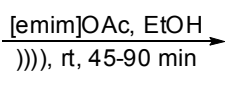

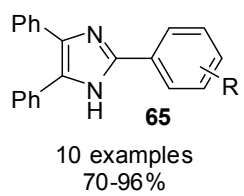

Scheme 18.

Joshi and co-workers (Joshi et al., 2010) reported the synthesis of 1,3-imidazoles (68) by the reaction of substituted aldehydes (67) with $o$-phenylenediamine (66) catalysed by $5 \mathrm{~mol} \%$ of tetrabutylammonium fluoride (TBAF) in water under ultrasonic irradiation at room temperature (Scheme 19). Quaternary ammonium fluoride salts are inexpensive and relatively non-toxic reagents and water is generally recognized to be a green solvent in organic synthesis. The reported synthesis thus represents a mild, chemoselective method for preparing these heterocycles.<smiles>Nc1ccccc1N</smiles>

66

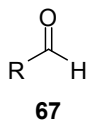<smiles>C#CC(C)(C)[Pb]</smiles>

67

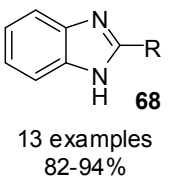

Scheme 19 .

Very recently, Arani and Safari (Arani \& Safari, 2011) reported a very efficient high yield (96-98\%) synthesis of 5,5-diphenylhydantoin (72) and 5,5-diphenyl-2-thiohydantoin (73) derivatives under mild conditions (Scheme 20). The reactions were performed in $\mathrm{DMSO} / \mathrm{H}_{2} \mathrm{O}$ with ultrasonic irradiation and catalyzed by $\mathrm{KOH}$.
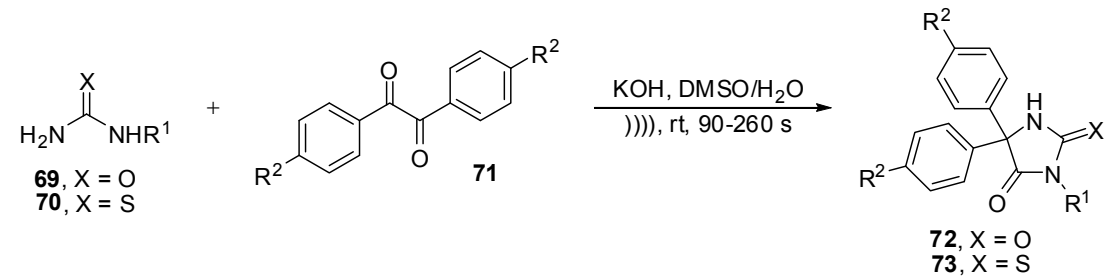

12 examples $96-99 \%$

Scheme 20 .

\subsection{Isoxazole derivatives}

Recently, $\mathrm{Li}$ and co-workers described a facile and economical procedure for the synthesis of spiro azole compounds (77) (Li et al., 2010). The one-pot synthesis of 3-aza-6,10-diaryl-2-oxa- 
spiro[4.5]decane-1,4,8-trione (77) from 1,5-diaryl-1,4-pentadien-3-one (74), dimethyl malonate (75), and hydroxylamine hydrochloride (76) in the presence of sodium hydroxide gave good yields at $50^{\circ} \mathrm{C}$ under ultrasound irradiation (Scheme 21).<smiles>O=C(/C=C/Br)/C=C/Br</smiles>

74<smiles>COC(=O)CC(=O)OC</smiles>

75
1. $\mathrm{NaOH}, \mathrm{MeOH},()))), 50^{\circ} \mathrm{C}$ 2. $\left.\left.\left.\mathrm{NH}_{2} \mathrm{OH} \bullet \mathrm{HCl}(76),()\right)\right)\right), 50{ }^{\circ} \mathrm{C}, 5-8 \mathrm{~h}$

Scheme 21.

A series of dihydroisoxazole derivatives (80) were prepared by the ultrasound-promoted cyclization reaction between chalcones (78) bearing a quinolinyl substituent and hydroxylamine hydrochloride (79) in the presence of sodium acetate in aqueous acetic acid solution (Scheme 22) (Tiwari et al., 2011). The sonochemical method gave better yields (87$90 \%$ ) of the products in shorter times (90-120 $\mathrm{min}$ ) than the corresponding thermal reactions $(72-78 \%$ in $6-7 \mathrm{~h})$.<smiles>[R]c1ccc(C(=O)/C=C/c2cc3ccccc3nc2Cl)cc1</smiles>

Scheme 22.

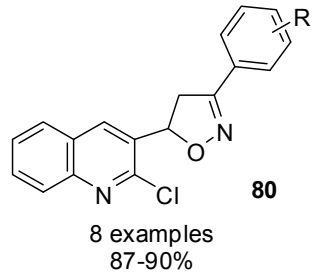

\subsection{Oxazole derivatives}

Ultrasound proved to be efficient for accelerating the cyclization reaction of aryl and methyl nitriles (81) with ethanolamine (82) catalyzed by $\mathrm{InCl}_{3}$ to give oxazole derivatives (83) (Scheme 23) (Moghadam et al., 2009). Products were obtained in $81-97 \%$ yields after $5-45$ minutes under sonication at room temperature.

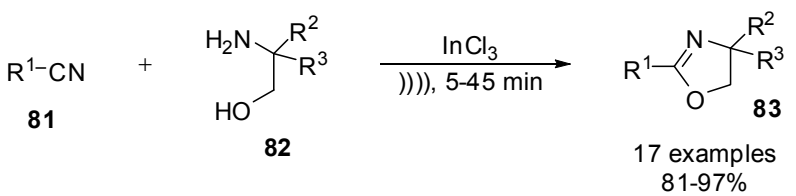

Scheme 23.

The same research group developed a new highly sulfonated carbon-based solid acid and employed it to catalyze reactions similar to those presented above under ultrasonic irradiation (Scheme 24) (Mirkhani et al., 2009). Reactions performed with a combination of the new catalyst and sonication were more efficient than those run without ultrasonic irradiation. 


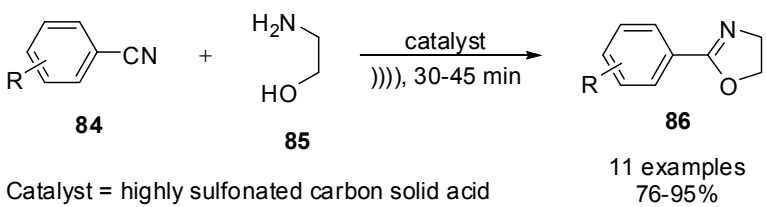

Scheme 24 .

\subsection{Thiazole derivatives}

In 2009, Noei and Khosropour (Noei \& Khosropour, 2009) reported a high yield, green protocol for the synthesis of 2,4-diarylthiazole derivatives (89 and 91) via the reaction of arylthioamides (88 and $\mathbf{9 0}$ ) with $a$-bromoacetophenones $(\mathbf{8 7})$ under ultrasonic irradiation in the ionic liquid $\left[\mathrm{bmim}^{\mathrm{B}} \mathrm{BF}_{4}(\right.$ Scheme 25$)$.

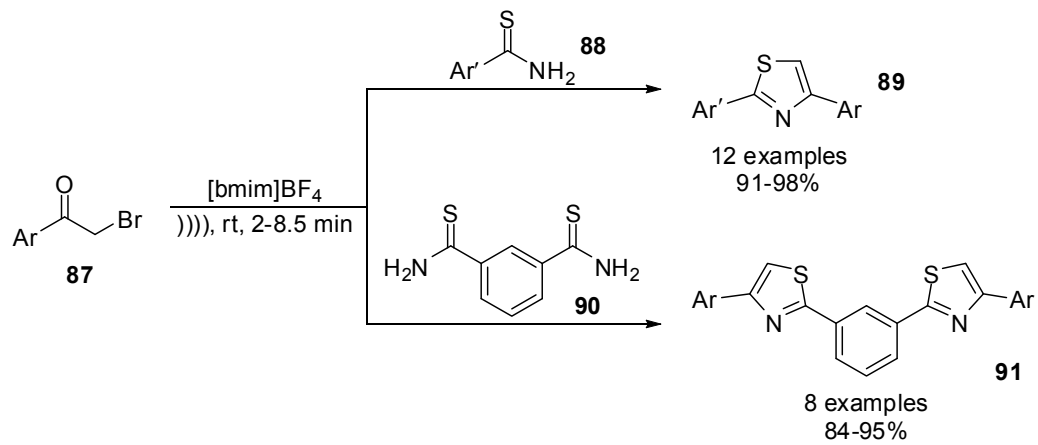

Scheme 25 .

Among the natural products containing a 1,3-thiazole ring, thiamine (aneurine, vitamin $\mathrm{B}_{1}$ ) is of great importance (Eicher \& Hauptmann, 2003). Several 2-( $N$-arylamino)-4-arylthiazoles (94) were prepared by the reaction of $a$-bromoacetophenones (92) with $N$-aryl substituted thioureas (93), as in the classical Hantzsch synthesis, but using ultrasonic irradiation (Scheme 26) (Gupta et al., 2010). This further confirmed that thiazole heterocycles can be conveniently synthesized in good yields (88-97\%) by the application of sonochemistry. The insecticidal activity of these 1,3-thiazoles was evaluated.

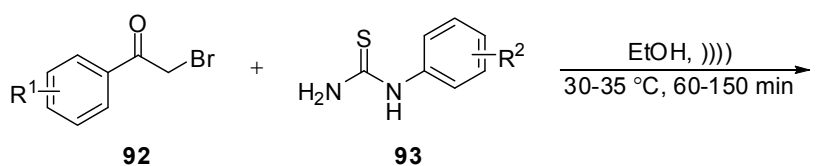

92
93

Scheme 26.

Recently, we reported an ultrasound-based procedure for the synthesis of pyrazolylsubstituted thiazoles (97) by the cyclization reaction between thiocarbamoyl-pyrazoles (95) and a-bromoacetophenone (96) (Venzke et al., 2011). The reactions occurred in only 15 
minutes in ethanol at room temperature, affording the pure products in $47-93 \%$ yields by simple filtration of the reaction mixture (Scheme 27).<smiles>[R]c1ccc(C2CC(c3ccccc3)=NN2C(N)=S)cc1</smiles>

95<smiles>CCOCC(=O)c1ccccc1</smiles>

96

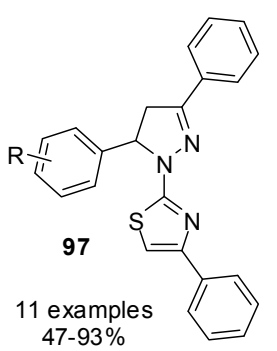

Scheme 27.

Recently, Mamaghani and co-workers described a sonochemical method for the preparation of iminothiazolidinones (102 and 103) (Mamaghani et al., 2011). Thioureas (100) were generated in situ and treated with a mixture of a suitable aldehyde (101), chloroform and 1,8diazabicyclo[5.4.0]undec-7-ene (DBU) in dimethyl ether (DME) under an inert atmosphere. Subsequent addition of aqueous $\mathrm{NaOH}$ at $0{ }^{\circ} \mathrm{C}$ and sonication furnished the products $(\mathbf{1 0 2}$ and 103) in 75-91\% yields (Scheme 28). A 1:1 mixture of regioisomers was observed when $\mathrm{N}$ cyclohexyl- $N$ '-ethylthiourea was employed. However, a regiosselective reaction took place with other substituents in the thiourea. The target molecules were obtained in better yields and much shorter reaction times using ultrasound than with conventional methodology.

$$
\mathrm{R}_{98}^{1} \mathrm{NH}_{2} \frac{\mathrm{R}^{2} \mathrm{NCS}(99)}{\mathrm{CH}_{2} \mathrm{Cl}_{2}}=\left[\mathrm{R}_{100}^{\mathrm{R}}\right.
$$

Scheme 28 .

Neuenfeldt and co-workers used ultrasonic power to promote the synthesis of thiazolidinones (108) (Neuenfeldt et al., 2011). The products were obtained in good yields from the reaction of in situ generated imines (106) with one equivalent of mercaptoacetic acid (107) in toluene, under sonication for 5 minutes (Scheme 29). The corresponding conventional thermal reactions in the absence of ultrasound also furnished similar yields of these heterocycles, but required much longer times (16 h).
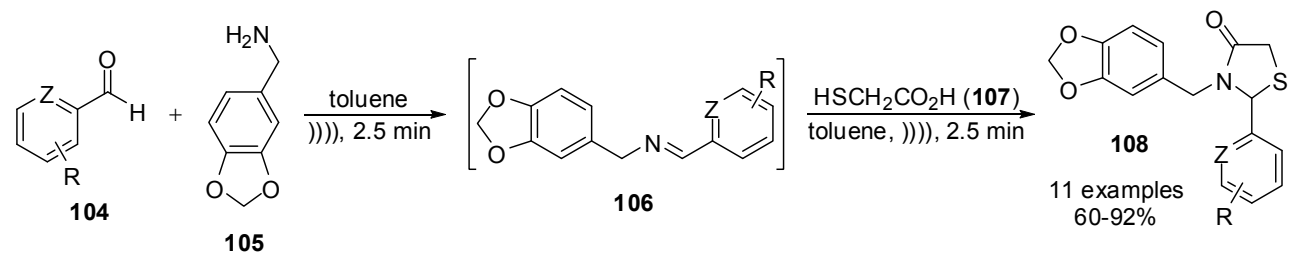

Scheme 29 . 
A library of spiro[indole-thiazolidinones] (112) was prepared sonochemically by a three component reaction in aqueous medium in the presence of cetyltrimethylammonium bromide (CTAB) as a phase transfer catalyst (Dandia et al., 2011). The reaction of indole-2,3diones (109), aryl- or heteroaryl-amines (110), and a-mercaptocarboxylic acids (111) under ultrasound for 40-50 minutes afforded the target molecules in good to excellent yields (8098\%) (Scheme 30).

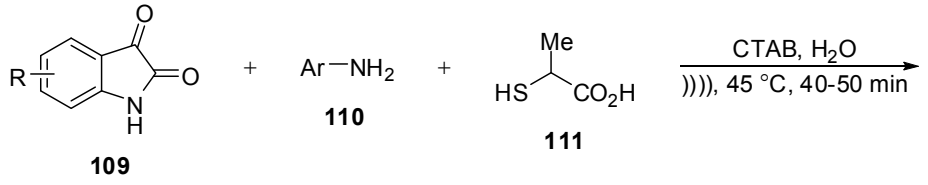

109

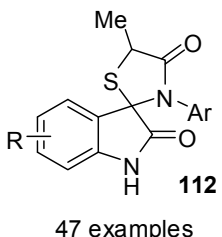

$80-98 \%$

Scheme 30 .

\subsection{Selenazole derivatives}

An ultrasound-mediated preparation of 1,3-selenazoles (115) was reported by Lalithamba and co-workers in 2010 (Lalithamba et al., 2010). The products were efficiently prepared by treatment of bromomethyl ketones (113) with selenourea (114) in acetone under ultrasonic irradiation for 5-10 minutes (Scheme 31).<smiles>[R]C([R2])C(=O)CC</smiles>

113<smiles>NC(=[Se])[SeH]</smiles>

114

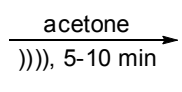

$5-10 \min$

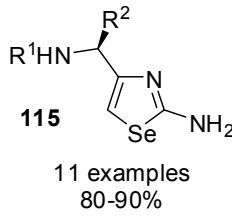

Scheme 31.

\section{Azoles with three heteroatoms}

\subsection{Triazole derivatives}

Ultrasonic activation of metal catalysts due to mechanical depassivation has been extensively exploited in organic synthesis. In this context, Cravotto and co-workers (Cravotto et al., 2010) reported an efficient copper-catalyzed azide-alkyne cycloaddition reaction for producing 1,2,3-triazole derivatives (118) using ultrasound or ultrasound and microwave simultaneously. Other activation methods were tested, but the best results were obtained when azides (116) and terminal alkynes (117) were sonicated in the presence of $\mathrm{Cu}$ turnings in dioxane $/ \mathrm{H}_{2} \mathrm{O}$ at $70{ }^{\circ} \mathrm{C}$ or DMF at $100{ }^{\circ} \mathrm{C}$ (Scheme 32). Substitution of water by DMF was required to prevent the formation of copper complexes that made the purification of the products difficult when 6-monoazido- $\beta$-cyclodextrin derivatives were utilized as starting materials. No particularly significant differences were observed between the efficiencies of the reactions performed using ultrasound or ultrasound/microwave irradiation. 


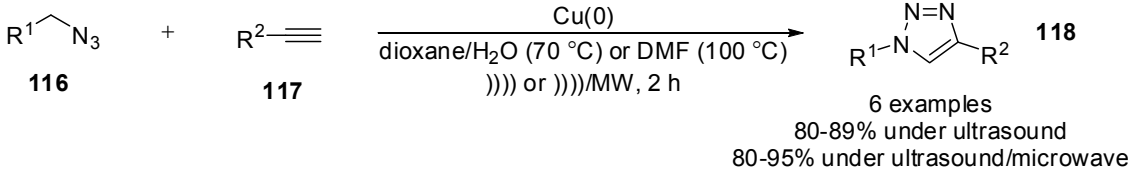

Scheme 32.

\subsection{Oxadiazole derivatives}

Azoles containing polyhaloalkyl groups are of considerable interest due to their potential herbicidal, fungicidal, insecticidal, analgesic, antipyretic, and anti-inflammatory properties. In addition, 1,2,4-oxadiazoles are reported to posses various types of biological activities (Elguero et al., 2002). Very recently, the rapid preparation of 1,2,4-oxadiazoles (121) under ultrasound irradiation was reported (Bretanha et al., 2011). The products were obtained with short reaction times (15 minutes) and in excellent yields (84-98\%) (Scheme 33).

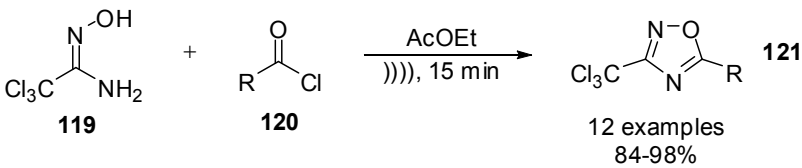

Scheme 33 .

\subsection{Thiadiazole derivatives}

1,3,4-Thiadiazole derivatives (124) were synthesized by the reaction of 1-methyl-5-oxo-3phenyl-2-pyrazolin-4-thiocarboxanilide (122) with a series of hydrazonyl halides or $N, N^{\prime}$ diphenyl-oxalodihydrazonoyl dichloride (123) in the presence of triethylamine (TEA) under ultrasonic irradiation (Scheme 34) (El-Rahman et al., 2009). The products were obtained in excellent yields in short reaction times.<smiles>[R]C([X])=NN[Ga]</smiles><smiles>[R]C1=NN([Al])C(=C2C(=O)N(C)N=C2c2ccccc2)C1=O</smiles>

Scheme 34 .

\section{Azoles with four heteroatoms}

\subsection{Tetrazole derivatives}

In 2010, Chermahini and co-workers reported the clay-catalyzed preparation of tetrazoles (127) under ultrasound (Scheme 35) (Chermahini et al., 2010). Compared to conventional heating, ultrasonic irradiation reduced the reaction times and increased the catalyst activity. Unfortunately, the yields obtained by this methodology were not specified by the authors. 


$$
\begin{aligned}
& \underset{125}{\mathrm{Ar}-\mathrm{CN}}+\underset{\mathrm{NaN}_{3}}{126} \frac{\text { clay, DMF or } \mathrm{H}_{2} \mathrm{O}}{7))), 70^{\circ} \mathrm{C}, 40-320 \mathrm{~min}} \underset{127}{\mathrm{Ar}} \\
& \text { Clay = Montmorillonite } \mathrm{K}-10 \text {, Kaolin } 10 \text { examples }
\end{aligned}
$$

Scheme 35 .

\section{Miscellaneous}

4-Sulphonyl-substituted pyrazoles (130) and isoxazoles (132) were synthesized via the onepot reaction of the carbanions of 1-aryl-2-(phenylsulphonyl)-ethanone (128) with several different hydrazonyl halides (129) or 1-aryl-2-bromo-2-hydroximinoethanones (131) in ethanol, respectively (Scheme 36) (Saleh et al., 2009). These reactions were accelerated by ultrasonic irradiation and the products were isolated in high yields (90-97\%).

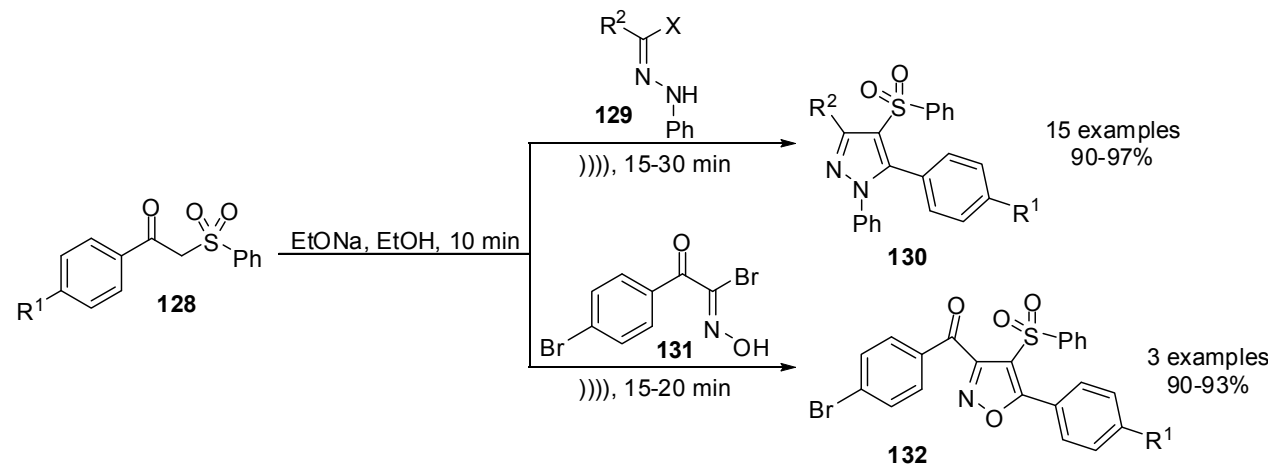

Scheme 36.

In 2009, Al-Zaydi (Al-Zaydi, 2009) reported the synthesis of triazole (135) and pyrazole (138) derivatives starting from arylhydrazononitriles (133) under ultrasonic irradiation (Scheme 37). The triazoles (135) were obtained via amidoxime intermediates (134) followed by cyclization with elimination of water. The pyrazoles (138) were prepared directly by reaction with chloroacetonitrile (136). This latter reaction involves the formation of a non-isolable intermediate (137) that undergoes intramolecular cyclization to give the final products (138).

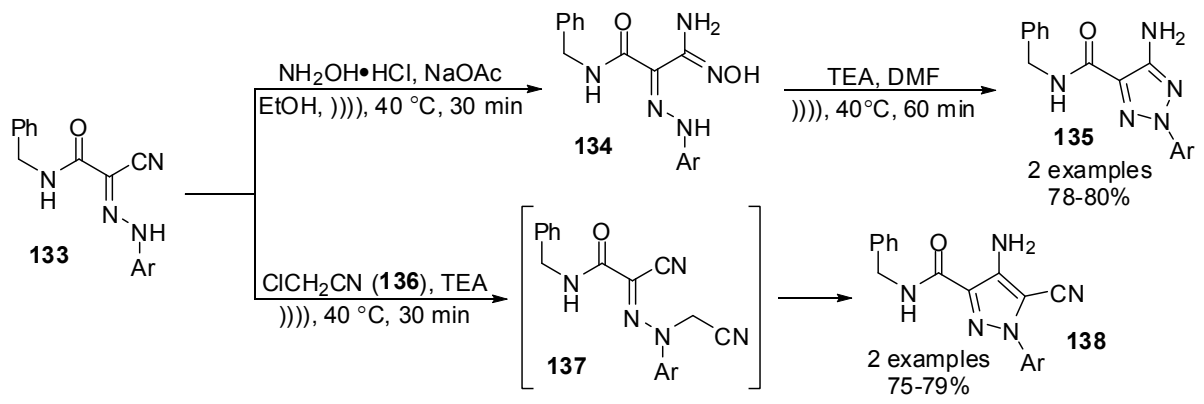

Scheme 37. 
In 2009, we described a scaled-up sonochemical method to convert acetylacetone (139) into structurally simple pyrazoles (140) or an isoxazole (141) in aqueous media (Scheme 38) (Silva et al., 2009). The products were obtained after sonication for only 10 minutes, as compared to 12 hours in the thermal reaction without ultrasound.

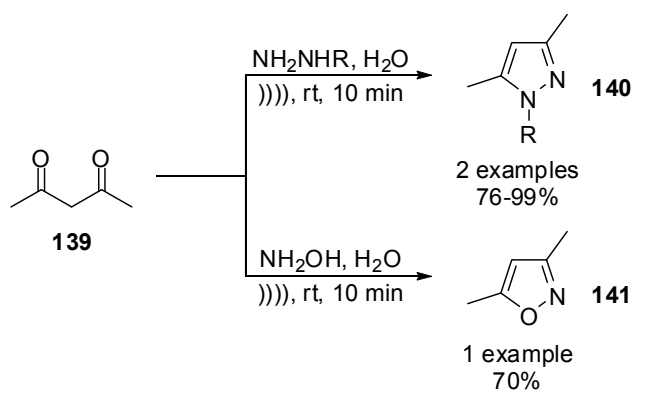

Scheme 38 .

As shown in Scheme 39 (Shinde et al., 2010), 2-ethyl-2-methyl-4H-chromen-4-ones (142) were transformed into semicarbazones (143) and thiosemicarbazones (146). The semicarbazones (143) could be sonochemically converted into selenadiazole derivatives (144) in 30 minutes by treatment with $\mathrm{SeO}_{2}$ in acetic anhydride. The same semicarbazones (143) afforded 1,2,3-thiadiazoles (145) under ultrasonic irradiation in 20 minutes in the presence of thionyl chloride. Similarly, sonication of the thiosemicarbazones (146) for 45 minutes in acetic anhydride produced the thiadiazolines (147) in good yields. Comparison of these results with those for the same reactions under microwave irradiation showed that the time required was longer and yields lower.

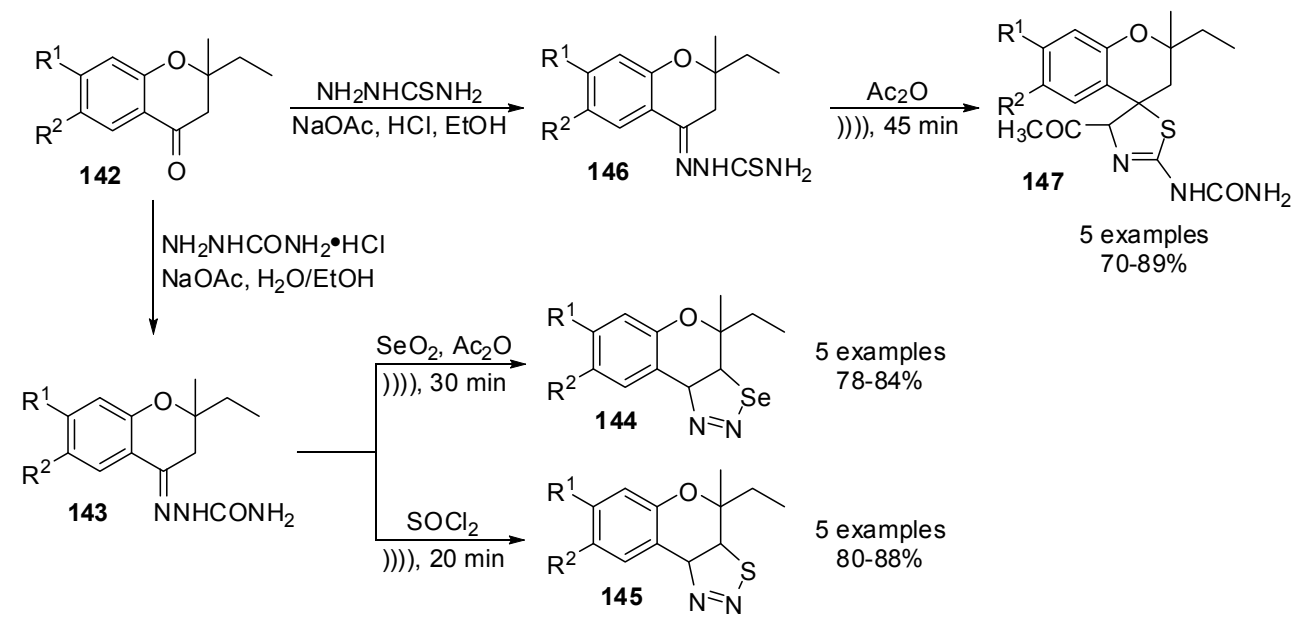

Scheme 39.

The syntheses of 1,3,4-thiadiazoles (149) and 1,3,4-triazoles (150) (Scheme 40) via the intramolecular cyclocondensation of benzofuran-substituted thiosemicarbazides (148) in 
acidic or basic media, respectively, has been reported (Shinde et al., 2010). The reactions were carried out employing ultrasound, microwaves and conventional conditions. Ultrasound afforded the best yields. The scope of these reactions was subsequently expanded by Shelke and co-workers (Scheme 41) (Shelke et al., 2010).

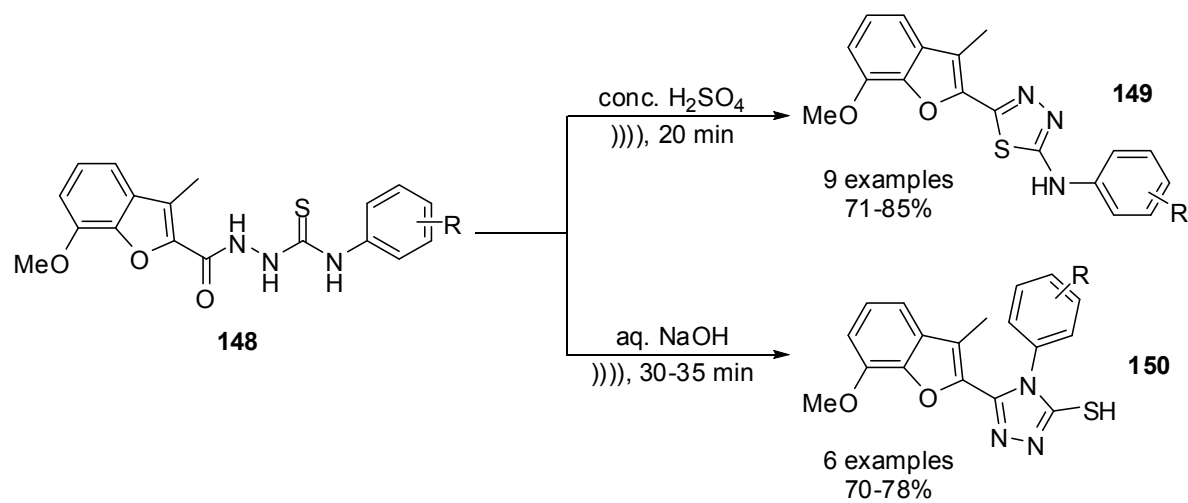

Scheme 40.

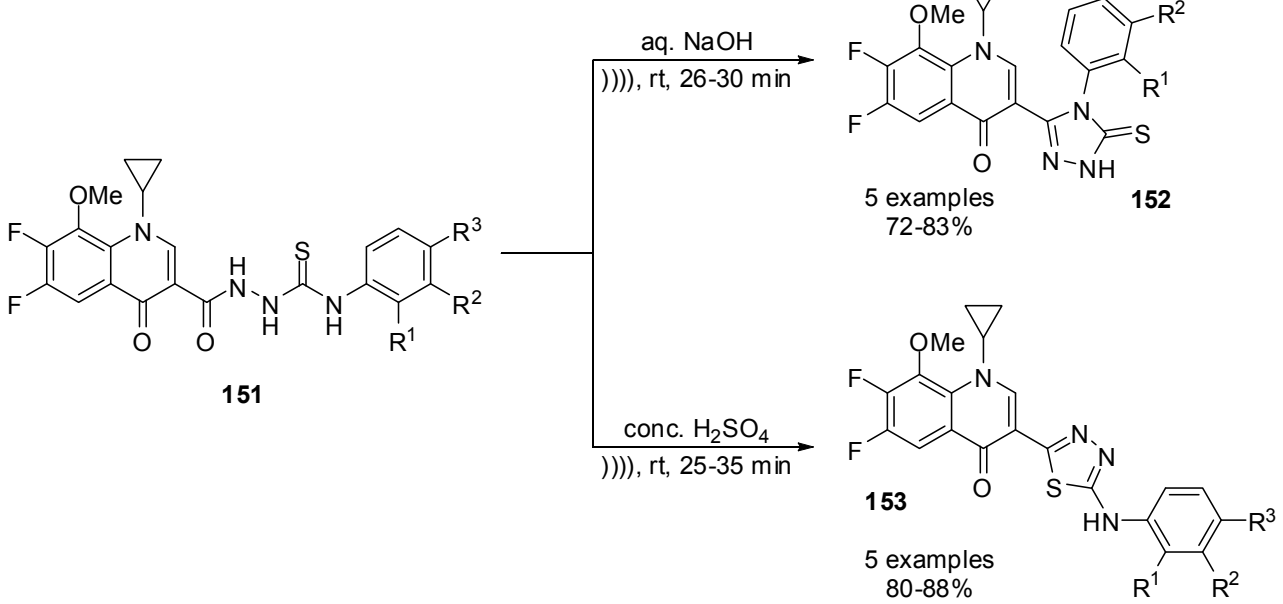

Scheme 41.

Yuan and Guo (Yuan \& Guo, 2011) reported the one-pot cyclocondensation of oaminothiophenol (155) or aromatic $o$-diamines (157) with aromatic aldehydes (154) in the presence of chlorotrimethylsilane $\left[\mathrm{TMSCl} / \mathrm{Fe}\left(\mathrm{NO}_{3}\right)_{3}\right]$ in dimethylformamide under ultrasonic irradiation for the preparation of benzothiazoles (156) and benzimidazoles (158) in $84-97 \%$ yields (Scheme 42 ). 


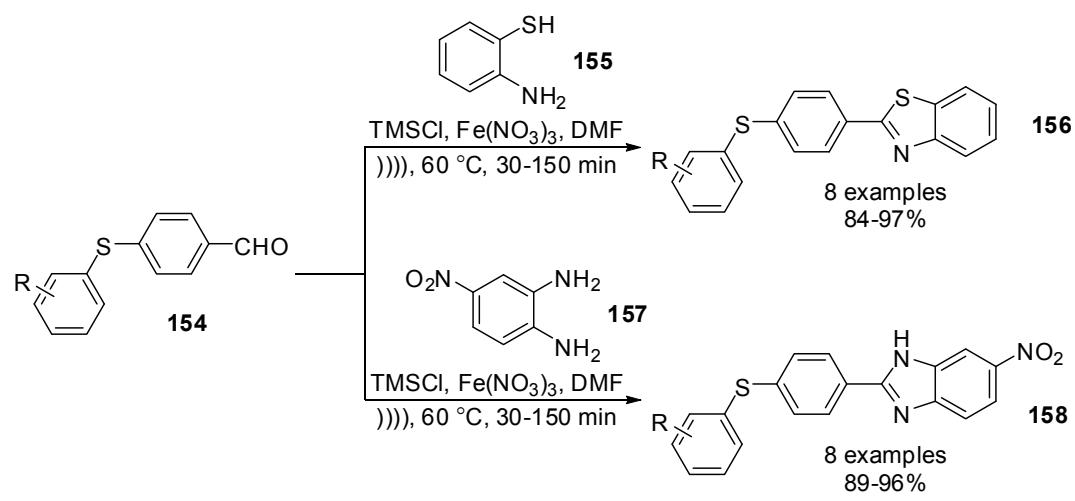

Scheme 42 .

\section{Conclusion}

As we have shown in this chapter, several convenient ultrasound-promoted synthetic methodologies have been established for the preparation of the title class of compounds. The main advantages of the use of ultrasound in azole synthesis are evident when compared with classical methodologies i.e., a reduction in the reaction times and an improvement in yields. Most of the papers covered by this review employed simple ultrasonic cleaning baths as energy sources. Although these low potency sources of ultrasonic radiation are usually less efficient than immersion sonication probes, requiring longer reaction times, cleaning baths are relatively inexpensive and widely available in chemistry laboratories.

\section{Acknowledgement}

The authors acknowledge CAPES and the CNPq (INCT Estudos do Meio Ambiente, grant 573.667/2008-0) for the financial support. FHQ is affiliated with INCT-Catalysis and NAPPhotoTech (the USP Research Consortium for Photochemical Technology) and thanks the $\mathrm{CNPq}$ for fellowship support.

\section{References}

Ahmad, M.; Siddiqui, H. L.; Zia-ur-Rehman, M. \& Parvez, M. (2010). Anti-oxidant and antibacterial activities of novel $N^{\prime}$-arylmethylidene-2-(3,4-dimethyl-5,5dioxidopyrazolo[4,3-c][1,2]benzothiazin-2(4H)-yl) acetohydrazides. European Journal of Medicinal Chemistry, Vol. 45, pp. 698-704.

Al-Mutairi, A. A.; El-Baih, F. E. M. \& Al-Hazimi, H. M. (2010). Microwave versus ultrasound assisted synthesis of some new heterocycles based on pyrazolone moiety. Journal of Saudi Chemical Society, Vol. 14, pp. 287-299.

Al-Zaydi, K. M. (2009). A simplified green chemistry approaches to synthesis of 2substituted 1,2,3-triazoles and 4-amino-5-cyanopyrazole derivatives conventional heating versus microwave and ultrasound as ecofriendly energy sources. Ultrasonics Sonochemistry, Vol. 16, pp. 805-809. 
Arani, N. M. \& Safari, V. J. (2011). A rapid and efficient ultrasound-assisted synthesis of 5,5diphenylhydantoins and 5,5-diphenyl-2-thiohydantoins. Ultrasonics Sonochemistry, Vol. 18, pp. 640-643.

Bretanha, L. C.; Teixeira, V. E.; Ritter, M.; Siqueira, G. M.; Cunico, W.; Pereira, C. M. P. \& Freitag, R. A. (2011). Ultrasound-promoted synthesis of 3-trichloromethyl-5alkyl(aryl)-1,2,4-oxadiazoles. Ultrasonics Sonochemistry, Vol. 18, pp. 704-707.

Cella, R. \& Stefani, H. A. (2009). Ultrasound in heterocycles chemistry. Tetrahedron, Vol. 65, pp. 2619-2641.

Chermahini, A. N.; Teimouri, A.; Momenbeik, F.; Zarei, A.; Dalirnasab, Z.; Ghaedi, A. \& Roosta, M. (2010). Clay-catalyzed synthesis of 5-substituent $1 H$-tetrazoles. Journal of Heterocyclic Chemistry, Vol. 47, pp. 913-922.

Cintas, P. \& Luche, J.-L. (1999). Green chemistry: the sonochemical approach. Green Chemistry, pp. 115-125.

Cravotto, G. \& Cintas, P. (2006). Power ultrasound in organic synthesis: moving cavitational chemistry from academia to innovative and large-scale applications. Chemical Society Reviews, Vol. 35, pp. 180-196.

Cravotto, G.; Fokin, V. V.; Garella, D.; Binello, A.; Boffa, L. \& Barge, A. (2010). Ultrasoundpromoted copper-catalyzed azide-alkyne cycloaddition. Journal of the Combinatorial Chemistry, Vol. 12, pp. 13-15.

Dandia, A.; Singh, R.; Bhaskaran, S. \& Samant, S. D. (2011). Versatile three component procedure for combinatorial synthesis of biologically relevant scaffold spiro[indolethiazolidinones] under aqueous conditions. Green Chemistry, Vol. 13, pp. 1852-1859.

Eicher, T. \& Hauptmann, S. (2003), In The Chemistry of Heterocycles, Second Edition. WileyVCH, Saarbrücken e Leipzig, pp. 154.

Elguero, J.; Goya, P.; Jagerovic, N.; Silva, A.M.S. (2002). In Targets in Heterocyclic System, Italian Society of Chemistry, Vol. 6, pp. 167.

El-Rahman, N. M. A.; Saleh, T. S. \& Mady, M. F. (2009). Ultrasound assisted synthesis of some new 1,3,4-thiadiazole and bi(1,3,4-thiadiazole) derivatives incorporating pyrazolone moiety. Ultrasonics Sonochemistry, Vol. 16, pp. 70-74.

Fry, A. J. \& Herr, D. (1978). Reduction of a,a'-dibromo ketones by ultrasonically dispersed mercury in protic solvents. Tetrahedron Letters, Vol. 19, pp. 1721-1724.

Gupta, R.; Gupta, N. \& Jain, A. (2010). Improved synthesis of chalcones and pyrazolines under ultrasonic irradiation. Indian Journal of Chemistry, Vol. 49B, pp. 351-355.

Gupta, R.; Sharma, D. \& Singh, S. (2010). Eco-friendly synthesis and insecticidal activity of some fluorinated 2-(N-arylamino)-4-arylthiazoles. Phosphorus, Sulfur, and Silicon, Vol. 185, pp. 1321-1331.

Joshi, R. S.; Mandhane, P. G.; Dabhade, S. K. \& Gill, C. H. (2010). Tetrabutylammonium fluoride (TBAF) catalysed synthesis of 2-arylbenzimidazole in water under ultrasound irradiation. Journal of the Chinese Chemical Society, Vol. 57, pp. 1227-1231.

Kanagarajan, V.; Ezhilarasi, M. R. \& Gopalakrishnan, M. (2011). 'One-pot' ultrasound irradiation promoted synthesis and spectral characterization of an array of novel 1,1'-(5,5'-(1,4-phenylene) bis(3-aryl-1H-pyrazole-5,1(4H,5H)-diyl))diethanones, a bis acetylated pyrazoles derivatives. Spectrochimica Acta Part A, Vol. 78, pp. 635-639.

Lalithamba, H. S.; Narendra, N.; Naik, S. A. \& Sureshbabu, V. V. (2010). Ultrasound mediated synthesis of 2-amino-1,3-selenazoles derived from Fmoc/Boc/Z-a-amino acids. Arkivoc, Vol. ix, 77-90. 
Li, J.-T.; Liu, X.-R. \& Sun, M.-X. (2010). Synthesis of glycoluril catalyzed by potassium hydroxide under ultrasound irradiation. Ultrasonics Sonochemistry, Vol. 17, pp. 5557.

Li, J.-T.; Yin, Y.; Li, L. \& Sun, M.-X. (2010). A convenient and efficient protocol for the synthesis of 5-aryl-1,3-diphenylpyrazole catalyzed by hydrochloric acid under ultrasound irradiation. Ultrasonics Sonochemistry, Vol. 17, pp. 11-13.

Li, J.-T.; Zhai, X.-L. \& Chen, G.-F. (2010). Ultrasound promoted one-pot synthesis of 3-aza6,10-diaryl-2-oxa-spiro[4.5]decane-1,4,8-trione. Ultrasonics Sonochemistry, Vol. 17, pp. 356-358.

Luche, J.-L. \& Damiano, J. C. (1980). Ultrasound in organic synthesis. 1. Effect on the formation of lithium organometallic reagents. Journal of the American Chemical Society, Vol. 102, pp. 7926-7927.

Machado, P.; Lima, G. R.; Rotta, M.; Bonacorso, H. G.; Zanatta, N. \& Martins, M. A. P. (2011). Efficient and highly regioselective synthesis of ethyl 1-(2,4-dichlorophenyl)- $1 \mathrm{H}$ pyrazole-3-carboxylates under ultrasound irradiation. Ultrasonics Sonochemistry, Vol. 18, pp. 293-299.

Mamaghani, M. \& Dastmard, S. (2009). One-pot easy conversion of Baylis-Hillman adducts into arylpyrazoles under ultrasound irradiation. Arkivoc, Vol. ii, pp. 168-173.

Mamaghani, M.; Loghmanifar, A. \& Taati, M. R. (2011). An efficient one-pot synthesis of new 2-imino-1,3-thiazolidin-4-ones under ultrasonic conditions. Ultrasonics Sonochemistry, Vol. 18, pp. 45-48.

Mason, T. J. (1997). Ultrasound in synthetic organic chemistry. Chemical Society Reviews, Vol. 26, pp. 443-451.

Mason, T. J. \& Lorimer, J. P. (2002). Applied sonochemistry: uses of power ultrasound in chemistry and processing, Wiley-VCH, ISBN 3-527-3020500, Weinheim.

Mirkhani, V.; Moghadam, M.; Tangestaninejad, S.; Mohammadpoor-Baltork, I. \& Mahdavi, M. (2009). Preparation of an improved sulfonated carbon-based solid acid as a novel, efficient, and reusable catalyst for chemo selective synthesis of 2-oxazolines and bis-oxazolines. Monatshefte für Chemie, Vol. 140, pp. 1489-1494.

Moghadam, M.; Mirkhani, V.; Tangestaninejad, S.; Mohammadpoor-Baltork, I. \& Kargar, H. (2009). $\mathrm{InCl}_{3}$ as an efficient catalyst for synthesis of oxazolines under thermal, ultrasonic and microwave irradiations. Journal of the Iranian Chemical Society, Vol. 6, pp. 251-258.

Nabid, M. R.; Rezaei, S. J. T.; Ghahremanzadeh, R. \& Bazgir, A. (2010). Ultrasound-assisted one-pot, three-component synthesis of $1 H$-pyrazolo[1,2-b]phthalazine-5,10-diones. Ultrasonics Sonochemistry, Vol. 17, pp. 159-161.

Neuenfeldt, P. D.; Duval, A. R.; Drawanz, B. B.; Rosales, P. F.; Gomes, C. R. B.; Pereira, C. M. P. \& Cunico, W. (2011). Efficient sonochemical synthesis of thiazolidinones from piperonilamine. Ultrasonics Sonochemistry, Vol. 18, pp. 65-67.

Noei, J. \& Khosropour, A. R. (2009). Ultrasound-promoted a green protocol for the synthesis of 2,4-diarylthiazoles under ambient temperature in $\left[\mathrm{bmim}_{\mathrm{B}} \mathrm{BF}_{4}\right.$. Ultrasonics Sonochemistry, Vol. 16, pp. 711-717.

Pathak, V. N.; Joshi, R.; Sharma, J.; Gupta, N. \& Rao, V. M. (2009). Mild and ecofriendly tandem synthesis, and spectral and antimicrobial studies of N1-acetyl-5-aryl-3(substituted styryl)pyrazolines. Phosphorus, Sulfur, and Silicon, Vol. 184, pp. 18541865. 
Pizzuti, L.; Martins, P. L. G.; Ribeiro, B. A.; Quina, F. H.; Pinto, E.; Flores, A. F. C.; Venzke, D. \& Pereira, C. M. P. (2010). Efficient sonochemical synthesis of novel 3,5-diaryl4,5-dihydro-1H-pyrazole-1-carboximidamides. Ultrasonics Sonochemistry, Vol. 17, pp. 34-37.

Pizzuti, L.; Piovesan, L. A.; Flores, A. F. C.; Quina, F. H. \& Pereira, C. M. P. (2009). Environmentally friendly sonocatalysis promoted preparation of 1-thiocarbamoyl3,5-diaryl-4,5-dihydro-1H-pyrazoles. Ultrasonics Sonochemistry, Vol. 16, pp. 728-731.

Richards, W. T. \& Loomis, A. L. (1927). The chemical effects of high-frequency sound waves. I. A preliminary survey. Journal of the American Chemical Society, Vol. 49, pp. 30863100 .

Rodrigues-Santos, C. E. \& Echevarria, A. (2011). Convenient syntheses of pyrazolo[3,4$b$ ]pyridin-6-ones using either microwave or ultrasound irradiation. Tetrahedron Letters, Vol. 52, pp. 336-340.

Saleh, T. S. \& El-Rahman, T. S. (2009). Ultrasound promoted synthesis of substituted pyrazoles and isoxazoles containing sulphone moiety. Ultrasonics Sonochemistry, Vol. 16, pp. 237-242.

Sant'Anna, G. S.; Machado, P.; Sauzem, P. D.; Rosa, F. A.; Rubin, M. A.; Ferreira, J.; Bonacorso, H. G.; Zanatta, N. \& Martins, M. A. P. (2009). Ultrasound promoted synthesis of 2-imidazolines in water: a greener approach toward monoamine oxidase inhibitors. Bioorganic \& Medicinal Chemistry Letters, Vol. 19, pp. 546-549.

Shekouhy, M. \& Hasaninejad, A. (2012). Ultrasound-promoted catalyst-free one pot four component synthesis of $2 H$-indazolo[2,1-b]phthalazine-triones in neutral ionic liquid 1-butyl-3-methylimidazolium bromide. Ultrasonics Sonochemistry, Vol. 19, pp. 307-313.

Shelke, K. F.; Sapkal, S. B.; Sonar, S. S.; Madje, B. R.; Shingate, B. B. \& Shingare, M. S. (2009). An efficient synthesis of 2,4,5-triaryl- $1 \mathrm{H}$-imidazole derivatives catalyzed by boric acid in aqueous media under ultrasound-irradiation. Bulletin of the Korean Chemical Society, Vol. 30, pp. 1057-1060.

Shelke, S.; Mhaske, G.; Gadakh, S. \& Gill, C. (2010). Green synthesis and biological evaluation of some novel azoles as antimicrobial agents. Bioorganic $\mathcal{E}$ Medicinal Chemistry Letters, Vol. 20, pp. 7200-7204.

Shinde, A. D.; Kale, B. Y.; Shingate, B. B. \& Shingare, M. S. (2010). Synthesis and characterization of 1-benzofuran-2-yl thiadiazoles, triazoles and oxadiazoles by conventional and non-conventional methods. Journal of the Korean Chemical Society, Vol. 54, pp. 582-588.

Shinde, A. D.; Sonar, S. S.; Shingate, B. B. \& Shingare, M. S. (2010). Synthesis and biological screening of novel thiadiazoles, selenadiazoles, and spirocyclic benzopyran by ultrasonic and microwave irradiation. Phosphorus, Sulfur, and Silicon, Vol. 185, pp. 1594-1603.

Silva, F. A. N.; Galluzzi, M. P.; Albuquerque, B.; Pizzuti, L.; Gressler, V.; Rivelli, D. P.; Barros, S. B. M. \& Pereira, C. M. P. (2009). Ultrasound irradiation promoted largescale preparation in aqueous media and antioxidant activity of azoles. Letters in Drug Design E Discovery, Vol. 6, pp. 323-326.

Tiwari, V.; Parvez, A. \& Meshram, J. (2011). Benign methodology and improved synthesis of 5-(2-chloroquinolin-3-yl)-3-phenyl-4,5-dihydroisoxazoline using acetic acid 
aqueous solution under ultrasound irradiation. Ultrasonics Sonochemistry, Vol. 18, pp. 911-916.

Venzke, D.; Flores, A. F. C.; Quina, F. H.; Pizzuti, L. \& Pereira, C. M. P. (2011). Ultrasound promoted greener synthesis of 2-(3,5-diaryl-4,5-dihydro-1H-pyrazol-1-yl)-4phenylthiazoles. Ultrasonics Sonochemistry, Vol. 18, pp. 370-374.

Yuan, Y.-Q. \& Guo, S.-R. (2011). TMSCl/Fe( $\left(\mathrm{NO}_{3}\right)_{3}$-Catalyzed synthesis of 2arylbenzothiazoles and 2-arylbenzimidazoles under ultrasonic irradiation. Synthetic Communications, Vol. 41, pp. 2169-2177.

Zang, H.; Su, Q.; Mo, Y.; Cheng, B.-W. \& Jun, S. (2010). Ionic liquid [emim]OAc under ultrasonic irradiation towards the first synthesis of trisubstituted imidazoles. Ultrasonics Sonochemistry, Vol. 17, pp. 749-751.

Zou, Y.; Wu, H.; Hu, Y.; Liu, H.; Zhao, X.; Ji, H. \& Shi, D. (2011). A novel and environmentfriendly method for preparing dihydropyrano[2,3-c]pyrazoles in water under ultrasound irradiation. Ultrasonics Sonochemistry, Vol. 18, pp. 708-712. 


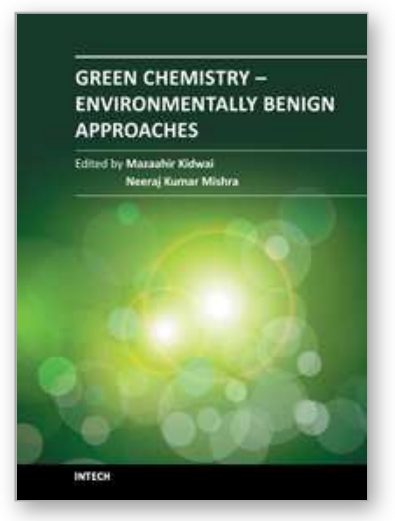

\author{
Green Chemistry - Environmentally Benign Approaches \\ Edited by Dr. Mazaahir Kidwai
}

ISBN 978-953-51-0334-9

Hard cover, 156 pages

Publisher InTech

Published online 23, March, 2012

Published in print edition March, 2012

Green chemistry is chemistry for the environment. It is really a philosophy and way of thinking that can help chemistry in research and production to develop more eco-friendly solutions. Green chemistry is considered an essential piece of a comprehensive program to protect human health and the environment. In its essence, green chemistry is a science-based non-regulatory and economically driven approach to achieving the goals of environmental protection and sustainable development. Combining the technological progress with environmental safety is one of the key challenges of the millennium. In this context, this book describes the environmentally benign approaches for the industries as well as chemical laboratories. In order to provide an insight into step change technologies, this book was edited by green organic chemists.

\title{
How to reference
}

In order to correctly reference this scholarly work, feel free to copy and paste the following:

Lucas Pizzuti, Márcia S.F. Franco, Alex F.C. Flores, Frank H. Quina and Claudio M.P. Pereira (2012). Recent Advances in the Ultrasound-Assisted Synthesis of Azoles, Green Chemistry - Environmentally Benign Approaches, Dr. Mazaahir Kidwai (Ed.), ISBN: 978-953-51-0334-9, InTech, Available from: http://www.intechopen.com/books/green-chemistry-environmentally-benign-approaches/recent-advances-inthe-ultrasound-assisted-synthesis-of-azoles

\section{INTECH}

open science | open minds

\author{
InTech Europe \\ University Campus STeP Ri \\ Slavka Krautzeka 83/A \\ 51000 Rijeka, Croatia \\ Phone: +385 (51) 770447 \\ Fax: +385 (51) 686166 \\ www.intechopen.com
}

\author{
InTech China \\ Unit 405, Office Block, Hotel Equatorial Shanghai \\ No.65, Yan An Road (West), Shanghai, 200040, China \\ 中国上海市延安西路65号上海国际贵都大饭店办公楼 405 单元 \\ Phone: +86-21-62489820 \\ Fax: +86-21-62489821
}


(C) 2012 The Author(s). Licensee IntechOpen. This is an open access article distributed under the terms of the Creative Commons Attribution 3.0 License, which permits unrestricted use, distribution, and reproduction in any medium, provided the original work is properly cited. 